\title{
LYSIS ENHANCEMENT: A NOVEL FORM OF INTERACTION BETWEEN $\beta$-LACTAM ANTIBIOTICS
}

\author{
D. Greenwood and F. O'Grady \\ Department of Bacteriology, St Bartholomew's Hospital, London EC1A 7BE
}

BETA-LACTAM antibiotics are well known to exert a number of concentration-dependent effects on Gram-negative bacilli that are reflected in different morphological changes in the bacteria. In a recent comprehensive comparison of the changes of opacity and bacterial morphology produced in cultures of Gram-negative bacilli by exposure to various $\beta$-lactam antibiotics (Greenwood and O'Grady, 1973a) we showed that the concentration ranges over which the different morphological effects occurred varied markedly between agents. Cephalexin, which is known to be a potent inducer of filament formation in Gram-negative bacilli-a response characteristic of low concentrations of other $\beta$-lactam antibiotics-was anomalous among those tested in that filamentation was the sole response of Escherichia coli to this agent over a very wide range of concentrations.

In the present study cephalexin was again shown to be unusual in that it showed synergy of a novel kind with other penicillins and cephalosporins.

\section{MATERIALS AND METHODS}

Cephalosporins were supplied by Glaxo Laboratories Ltd and ampicillin by Beecham Research Laboratories Ltd. Suitable concentrations of antibiotic were freshly prepared in sterile distilled water as required.

Strains of $E$. coli were isolated from infected urine in the diagnostic bacteriology department of this hospital. Two strains, designated ECSA1 and Far, which are respectively ampicillin sensitive and ampicillin resistant, were intensively studied.

Growth medium was the "complete" broth having an osmolality of $c .325$ mOsmoles per kg previously described (Greenwood and O'Grady, 1973a). Turbidimetric studies were made with the 12-channel opacity-monitoring device described by Mackintosh et al. (1973). Antibiotic was added at a point in the mid-to-late logarithmic phase of growth corresponding to a viable count of either c. $5 \times 10^{7}$ organisms per $\mathrm{ml}$ (30\% maximum opacity) or $10^{7}$ organisms per $\mathrm{ml}(10 \%$ maximum opacity).

Combinations of antibiotic were added together at the $30 \%$ opacity point. Where they were added separately, the first addition was made at $10 \%$ and the second at $30 \%$ opacity.

\section{RESULTS}

The results were expressed as the intervals between antibiotic addition and a sharp drop in opacity indicating lysis of the culture.

As previously reported (Greenwood and O'Grady, 1973a) addition of cephaloridine or cephalothin to the ampicillin-sensitive strain ECSA1 or the ampicillin-resistant strain Far caused lysis after an interval that depended on the concentration of the agent. Sufficient cephalexin to produce a concentration of $8 \mu \mathrm{g}$ per ml caused delayed lysis of the culture after $1 \frac{1}{2}$ to $2 \mathrm{~h}$ if added at $10 \%$ opacity, but was without effect on the growth curve if added at $30 \%$ opacity. The characteristic filamentation response of $E$. coli to this antibiotic was nevertheless demonstrated microscopically in both cases. When sufficient cephalexin to produce a concentration of $8 \mu \mathrm{g}$ per $\mathrm{ml}$ was added at the same time, the concentration of cephaloridine or cephalothin required to produce a given lytic effect was approximately halved (table I). 
When the same concentration of cephalexin $(8 \mu \mathrm{g}$ per $\mathrm{ml})$ was allowed to act on the culture for about $40 \mathrm{~min}$. before the addition of the second agent the concentration of cephaloridine or cephalothin needed to produce a given lytic effect was reduced to approximately one quarter (table I). With the ampicillin-sensitive strain ECSA1 similar results were obtained with cephalexin and ampicillin, but when the antibiotic additions were made in the reverse order-ampicillin before cephalexin-enhancement of the early lytic effect was not found (table II).

The results obtained with the two strains reported here were confirmed, with minor differences, for three other strains of $E$. coli, two of which were resistant to ampicillin.

\section{Discussion}

Three types of interaction are now known to occur between $\beta$-lactam agents. The best known of these is the $\beta$-lactamase inhibition effect (Abraham and Newton, 1956; HamiltonMiller, Smith and Knox, 1964; Sutherland and Batchelor, 1964) where some $\beta$-lactam antibiotics, such as methicillin, which are inactive against Gram-negative bacilli, are nevertheless stable to enterobacterial penicillinase for which they have a high affinity. Such agents may be used to sequester the penicillinase of a resistant organism and allow a penicillinase-sensitive $\beta$-lactam agent to act.

A second type of interaction has recently been described between cephalexin and FL1060 (a 6- $\beta$-amidinopenicillanic acid: Lund and Tybring, 1972; Greenwood and O'Grady, $1973 b$ ) which in combination produce the "typical penicillin effect" of spheroplast formation through discrete cell-wall lesions which neither agent can produce alone (Greenwood and O'Grady, 1973c).

The third form of interaction, which is reported here, resembles this in that it also depends on the dominant action of cephalexin on E.coli, which is to inhibit division, giving rise to long, snake-like filaments (Muggleton et al., 1969; Russell and Fountain, 1970). With most $\beta$-lactam antibiotics, filament formation is seen only at low and generally sub-inhibitory concentrations, but with cephalexin this is the only effect seen over a very wide range of concentrations (Fujii, Konno and Ubukata, 1970; Greenwood and O'Grady, 1973a). It is no doubt because of this that exposure to concentrations of cephalexin below $128 \mu \mathrm{g}$ per ml produces lysis of $E$. coli only after a long delay, and then only if antibiotic is added sufficiently early in the growth cycle for the filaments to grow long enough to lyse before the culture enters the stationary phase (Greenwood and O'Grady, 1973a). Beta-lactam antibiotics such as cephalothin and ampicillin differ from cephalexin in that the concentrations that

TABLE I

Enhancement of lysis by cephalothin or cephaloridine produced by prior exposure to cephalexin

\begin{tabular}{|c|c|c|c|c|c|c|}
\hline \multirow{4}{*}{$\begin{array}{c}\text { Strain } \\
\text { designation }\end{array}$} & \multicolumn{6}{|c|}{$\begin{array}{l}\text { Concentration ( } \mu \mathrm{g} \text { per ml) causing lysis } \\
\text { within } 15 \mathrm{~min} \text {. of addition of }\end{array}$} \\
\hline & \multicolumn{3}{|c|}{ cephalothin } & \multicolumn{3}{|c|}{ cephaloridine } \\
\hline & \multirow[t]{2}{*}{ alone } & plus & after & \multirow[t]{2}{*}{ alone } & plus & after \\
\hline & & \multicolumn{2}{|c|}{$\begin{array}{c}\text { cephalexin } \\
(8 \mu \mathrm{g} \text { per } \mathrm{ml})\end{array}$} & & \multicolumn{2}{|c|}{$\begin{array}{c}\text { cephalexin } \\
(8 \mu \mathrm{g} \text { per } \mathrm{ml})\end{array}$} \\
\hline ECSA 1 & 64 & 32 & 16 & 16 & 8 & 4 \\
\hline Far & 64 & 32 & 16 & 32 & 16 & 8 \\
\hline
\end{tabular}


produce filamentation and the emergence of spheroplasts are not widely dissociated (Greenwood and O'Grady, 1973a).

The simplest explanation of the "synergy" of such agents with cephalexin is that they exert a limited lytic activity at lower concentrations than those that cause rapid lysis. If the bacterial population is converted to long, non-septate filaments, this limited activity will exert a more extensive effect because injury at one point of a filament can produce loss of substance equivalent to the lysis of many normal bacteria.

We have previously argued (Greenwood and O'Grady, 1973a) that the concentrationdependent morphological effects of penicillins and cephalosporins stem from the inhibition of two distinct enzymes-one involved in cell division and one involved in generalised cellwall synthesis (Greenwood and O'Grady, 1973d) -which are differentially inhibited by $\beta$-lactam agents over different concentration ranges. According to this hypothesis, rapid lysis is due to osmotic rupture after the simultaneous inhibition of both enzymes. The residual activity postulated to account for the synergy reported here refers to the inhibition of generalised cell-wall synthesis. With cephalexin itself, which inhibits cell division only at concentrations below about $500 \mu \mathrm{g}$ per $\mathrm{ml}$ and hence does not cause lysis except at very high concentrations, such residual activity should be absent; and in keeping with this, enhancement of lysis was not observed when cephalexin was added to cultures in which filamentation had been previously induced by sub-inhibitory concentrations of ampicillin (table II).

Interesting though this is in relation to the mode of action of $\beta$-lactam agents, the need to expose the culture to cephalexin for sufficient time to allow filaments to develop before adding the second agent makes it doubtful whether this kind of interaction offers much therapeutic promise.

\section{SUMMARY}

A novel form of synergy has been observed to occur between cephalexin and certain other $\beta$-lactam antibiotics. In the presence of cephalexin a reduction was found in the concentration of other $\beta$-lactam agents needed to induce lysis of Escherichia coli; the effect was particularly marked when cephalexin was allowed to act for a short time before the addition of the second agent.

The basis of this type of synergy-which is not likely to be of therapeutic value-is discussed in terms of a theory previously put forward, which suggests that penicillins and cephalosporins have two distinct sites of action in Gram-negative bacilli.

We thank Glaxo Laboratories Ltd for financial assistance.

\section{TABLE II}

Effect of order of adding cephalexin $(8 \mu \mathrm{g} p \mathrm{pr} \mathrm{ml})$ and ampicillin $(4 \mu \mathrm{g}$ per $\mathrm{ml})$ on enhancement of lysis of strain no. ECSAI

\begin{tabular}{ll|c}
\hline$\overbrace{10}^{\text {Antibiotic added at opacity (\%) of }}$ & Time (h) to lysis \\
& 30 & \\
Cephalexin & None & 2.0 \\
None & Ampicillin & 1.5 \\
Cephalexin & Ampicillin & 0.25 \\
None & Cephalexin & No lysis \\
Ampicillin & None & 0.75 \\
Ampicillin & Cephalexin & 0.75 \\
\hline
\end{tabular}




\section{REFERENCES}

Abraham, E. P. and Newton, G. G. F. 1956. A comparison of the action of penicillinase on benzylpenicillin and cephalosporin $\mathbf{N}$ and the competitive inhibition of penicillinase by cephalosporin C. Biochem. J., 63, 628 .

FujII, R., Konno, M. AND UbuKata, K. 1970. The filamentous shape of Escherichia coli treated with cephalexin in higher concentration than the minimum inhibitory concentration and its clinical significance. In Progress in antimicrobial and anticancer chemotherapy, vol. 1, edited by $\mathrm{H}$. Umezawa, Baltimore and Manchester, p. 374.

Greenwood, D. AND O'Grady, F. 1973a. Comparison of the responses of Escherichia coli and Proteus mirabilis to seven beta-lactam antibiotics. J. infect. Dis., 128, 211.

Greenwood, D. AND O'Grady, F. 1973b. FL1060: a new beta-lactam antibiotic with novel properties. J. clin. Path., $26,1$.

Greenwood, D. ANd O'Grady, F. 1973c. The two sites of penicillin action in Escherichia coli. J. infect. Dis., 128, 791.

Greenwood, D. ANd O'Grady, F. 1973d. Penicillin and the site of wall growth in Gramnegative bacilli. Naturwissenschaften, 60, 435 .

Hamilton-Miller, J. M. T., Smith, J. T. AND Knox, R. 1964. Potentiation of penicillin action by inhibition of penicillinase. Nature, Lond., 201, 867.

Lund, F. AND TyBring, L. 1972. 6- $\beta$-amidinopenicillanic acids-a new group of antibiotics. Nature, New Biol., Lond., 236, 135.

Mackintosh, I. P., O'Grady, F., Greenwood, D., Watson, B. W., Crichton, T. C., PIPER, R. AND FERRER, A. 1973. A twelve channel bacterial growth monitoring system. Bio-med. Engng, 8, 514.

Muggleton, P. W., O’Callaghan, C. H., Foord, R. D., Kirby, S. M. and Ryan, D. M. 1969. Laboratory appraisal of cephalexin. Antimicrob. Agents Chemother., 1968, p. 353.

Russell, A. D. AND Fountain, R. H. 1970. The effect of some cephalosporins on Escherichia coli. Postgrad. med. J., 46, October suppl., 43.

Sutherland, R. AND Batchelor, F. R. 1964. Synergistic activity of penicillins against penicillinase-producing Gram-negative bacilli. Nature, Lond., 201, 868. 